\title{
ВЛИЯНИЕ ГЛУТАТИОН-СОДЕРЖАЩИХ ДИНИТРОЗИЛЬНЫХ КОМПЛЕКСОВ ЖЕЛЕЗА НА ОКИСЛИТЕЛЬНЫЙ МЕТАБОЛИЗМ КРОВИ КРЫС
}

\author{
А.К. Мартусевич, А.Г. Соловьева, Л.К. Ковалева \\ Приволжский исследовательский медицинский университет, Нижний Новгород, Россия \\ Кубанский государственный медицинский университет, Краснодар, Россия
}

РЕЗЮМЕ. Изучали влияние динитрозильных комплексов железа (ДНКЖ) с глутатионовыми лигандами на параметры окислительного метаболизма крови крыс. Сопоставляли интенсивность липопероксидации, антиоксидантную активность и уровень малонового диальдегида в плазме крови крыс, получавших курс внутрибрюшинных инъекций физиологического раствора и раствора ДНКЖ $(0,15 ; 0,30 ; 0,45$ и 0,60 мМ). Показано наличие у ДНКЖ антиоксидантного эффекта, причем его выраженность демонстрирует нелинейную зависимость от их дозы с оптимумом в диапазоне $0,3-0,45$ мМ.

КЛЮЧЕВЫЕ СЛОВА: кровь, окислительный метаболизм, динитрозильные комплексы железа.

\section{THE INFLUENCE OF GLUTATHIONE-CONTAINING DINITROSYL IRON COMPLEXES ON BLOOD OXIDATIVE METABOLISM IN RATS}

\author{
A.K. Martuseivch, A.G. Soloveva, L.K. Kovaleva \\ Privolzhsky Research Medical University, Nizhny Novgorod, Russia \\ Kuban State Medical University, Krasnodar, Russia
}

ABSTRACT. We studied the influence of dinitrosyl iron complexes (DNIC) on oxidative metabolism in rats' blood. The intensity of lipid peroxidation, antioxidant activity and malonic dialdehyde level were estimated in blood samples from rats, treating with injections of saline (control) or saline with $0.15 ; 0.30 ; 0.45$ and $0.60 \mathrm{MM}$ of DNIC. Our results demonstrated that DNIC has antioxidant properties. This effect is dose-dependent with optimum in $0.3-0.45 \mathrm{mM}$.

KEYWORDS: blood, oxidative metabolism, dinitrosyl iron complexes.

\section{ВВЕДЕНИЕ}

Биологические эффекты экзогенных динитрозильных комплексов железа (ДНКЖ) с различными лигандами раскрыты недостаточно подробно. Наши экспериментальные данные, полученные в исследованиях in vivo (Мартусевич и др., 2015), а также сведения, опубликованные другими авторами (Vanin et al., 2009), дают основание предполагать наличие у динитрозильных комплексов железа антиоксидантных свойств.

Цель работы - изучение дозозависимости действия экзогенных ДНКЖ на параметры окислительного метаболизма крови крыс.

\section{МАТЕРИАЛЫ И МЕТОДЫ}

Эксперимент выполнен на 60 крысах-самцах Вистар, разделенных на 6 равных по численности групп. Первая группа животных была интактной. Крысам, включенным в остальные группы, в течение 10 дней ежедневно осуществляли внутрибрюшинное введение 1 мл 0,9\%-ного раствора хлорида натрия. При этом животным третьей-шестой групп во вводимый раствор добавляли ДНКЖ (концентрация - 0,15; 0,30; 0,45 и 0,60 мМ соответственно). Динитрозильные комплексы железа синтезировали по методике Ванина (2009). В плазме крови крыс методом $\mathrm{Fe}^{2+}$-индуцированной биохемилюминесценции (аппарат БХЛ-06) изучали активность про- и антиоксидантных систем. Уровень малонового диальдегида (МДА) в плазме крови оценивали по методу Сидоркина, Чулошниковой (1993). Результаты исследования были обработаны в программном пакете Statistica 6.0. 


\section{РЕЗУЛЬТАТЫ И ОБСУЖДЕНИЕ}

Установлено, что интенсивность липопероксидации демонстрировала выраженную, но нелинейную зависимость от концентрации вводимых ДНКЖ. Так, при введении животным минимальной дозы соединения (1 мл 0,15 мМ раствора) не наблюдали отклонений показателя. В случае увеличения концентрации вещества в растворе (0,3 мМ и выше) отмечали снижение интенсивности процессов липопероксидации, достигающее минимума при проведении курса инфузий 0,45 мМ раствора ДНКЖ $(p<0,05)$. Дальнейшее увеличение дозы донора NO оказывает менее выраженное действие на уровень параметра.

Не наблюдали существенных сдвигов общей антиоксидантной активности плазмы крови у крыс, получавших инфузии только физиологического раствора, тогда как при добавлении в него ДНКЖ в любой из изученных концентраций отмечали нарастание значения параметра. В наименьшей степени данная тенденция была выражена для минимальной дозы соединения $(0,15 \mathrm{MM})$. В диапазоне $0,15-0,45$ мМ ДНКЖ регистрировали прогрессивное увеличение антиоксидантной активности плазмы: для концентраций 0,$15 ; 0,30$ и $0,45 \mathrm{mM}$ оно составило 1,$08 ; 1,24$ и 1,31 раза соответственно ( $p<0,1-$ для наименьшей концентрации и $p<0,05$ - для остальных). Дальнейшее нарастание количества соединения (до 0,6 мМ) обеспечивало обратный эффект: общая антиоксидантная активность в этом случае возрастала лишь на $13 \%(p<0,05)$.

Введение средней концентрации соединения (до 0,3 мМ) снижает уровень МДА в плазме крови (-14\%; $p<0,05)$ по сравнению со здоровыми особями. Аналогичная динамика отмечена и при использовании концентрации $0,45 \mathrm{mM}(-12 \% ; p<0,05)$. При этом дальнейшее увеличение дозы ДНКЖ (до 4-кратной минимальной) способствовало менее выраженному падению уровня изучаемого метаболита $(-7 \% ; p<0,05)$.

\section{ВЫВОДЫ}

Исследования свидетельствуют о наличии антиоксидантного эффекта у глутатион-содержащих ДНКЖ, причем выраженность этих свойств демонстрирует нелинейную зависимость от их дозы с оптимумом в диапазоне $0,3-0,45$ мМ.

\section{Сиисок литературы / References}

1. Мартусевич А.К., Соловьева А.Г., Давылюк А.В., Перетягин С.П. Влияние динитрозильных комплексов железа на параметры окислительного метаболизма при экспериментальной термической травме. Экспериментальная и клиническая фармакология. 2015; 78 (7): 15-19 (Martusevich A.K., Solov'eva A.G., Davydjuk A.V., Peretjagin S.P. Vlijanie dinitrozil'nyh kompleksov zheleza na paramet-ry okislitel'nogo metabolizma pri jeksperimental'noj termicheskoj travme. Jeksperimental'naja i klinicheskaja farmako-logija. 2015; 78 (7): 15-19).

2. Vanin A.F. Dinitrosyl-iron complexes with thiolate ligands: physico-chemistry, biochemistry and physiology. Nitric Oxide Biol. Chem. 2009; 21: 136-149. 